\title{
УСТОЙЧИВОСТЬ И ПОВТОРЯЕМОСТЬ ПРЕСТУПНОЙ ДЕЯТЕЛЬНОСТИ В ПРОСТРАНСТВЕ И ВРЕМЕНИ КАК ЗАКОНОМЕРНОСТЬ СЕРИЙНЫХ УБИЙСТВ
}

\begin{abstract}
Е. С. Крюкова
Московский государственный университет илени М. В. Лолоносова

Поступила в редакцию 4 июня 2020 г.

Аннотация: рассматриваются закономерности объективной действительности, проявляюшиеся во врелени совершения серийньх убийств, особенности выбора времени и фбактов, определяюших его, а также устойчивость, повторяелость и разновреленность преступных эпизодов, имеющих сходнье чертыл.
\end{abstract}

Ключевые слова: крилиналистика, законолерность, время, серийное убийство, "период элоционального остывания", хронология.

\begin{abstract}
: the article discusses the patterns of time of the commission of serial killings, especially the choice of time and facts that determine it. Sustainability, repeatability and the diversity of criminal episodes that have similar features.

Key words: criminalistics, forensic science, pattern, time, serial killing, "cooling-off period", chronology.
\end{abstract}

В российской и зарубежной литературе нет единого определения понятия «серийное убийство» и понимания феномена серийного убийства. Встречаются различные, в том числе весьма противоречивые, точки зрения на понятие, признаки, виды, характерные черты серийного убийства. Свои мнения давали представители различных научных на๓ правлений (Ю. М. Антонян, П. П. Баранов, В. И. Батищев, О. А. Буха을 новский, В. Н. Исаенко, О. Н. Кузнецова, В. А. Образцов, А. А. Протасевич, А. О. Протопопов, Ю. М. Самойлов, Л. А. Соя-Серко, И. В. Усанов, А. С. Фомина, А. В. Хамуков и др.). Из зарубежных ученых можно выделить работы Б. Арриго, Р. и С. Холмсов, Дж. Де Бургера (в соавторстве), Дж. Фокса и Дж. Левина (в соавторстве), Р. Мортона, Е. Хикей, К. Бартола, С. Эггера и др.

Предлагаем понимать серийное убийство как лишение жизни двух и более лии, совершенное с вреленнылм интервалом между эпизодали, в условиях неочевидности, с прялым улыслом одним лищом (в редких случаях группой лии по предварительнолу сговору), характеризующееся сходной мотивацией ${ }^{1}$ В целом для него характерны сходство обстановки

${ }^{1}$ См.: Крюкова $E$. C. Криминалистический взгляд на понятие серийное убийство // Юридический вестник Дагестанского гос. ун-та. 2013. № 2. С. 93-102 ; $E e$ же. Характеристика современного преступника и его преступной деятельности (на примере серийных убийств) // Вестник Моск. ун-та. Серия 11, Право. 2014. № 4. С. 85-93 ; Ее же. Взаимосвязь между случаями жестокого обращения

(C) Крюкова Е. С., 2021 
и способа совершения преступления, совпадение характеристик личности потерпевших, характера нанесенных повреждений ${ }^{2}$ и иных признаков, отобразившихся в следовой информации, дающих основания для выдвижения версии об их совершении одним лицом (лицами), получением удовольствия как своеобразной эмоциональной реакции на совершенное преступление, однако указанные особенности намеренно не включены в определение, так как встречаются не во всех случаях и требуют отдельных пояснений.

В ходе изучения проблематики нами было проанализировано более 375 эпизодов убийств, имеющих признаки серийности, совершенных в России, позволившие выявить некоторые закономерности серийного убийства и существующие взаимосвязи основных элементов криминалистической характеристики данной категории убийств, в том числе устойчивость и повторяелость преступной деятельности в пространстве и врелени. Данный подход выявления закономерностей механизма серийных убийств и использования сведений о них в процессе раскрытия, расследования и предупреждения преступлений уникален, ранее не становился предметом специальных криминалистических исследований и, надеемся, породит дискуссию и дальнейшие исследования ученых в этом направлении.

Расследование серийных убийств как неочевидных убийств обычно проводится в сложной следственной ситуации, которая отличается недостаточным количеством данных об обстоятельствах, подлежащих установлению по уголовному делу, неизвестностью данных о виновном. Однако убийства, оставшиеся нераскрытыми, являются, как правило, результатом неумения пользоваться всеми теми средствами, которые дает в руки правоохранительным органам криминалистика, в том числе криминалистической характеристики как комплекса устойчивых, повторяющихся существенных черт преступления ${ }^{3}$. Преступники не обнаруживаются не в силу особо ухищренных способов совершения преступления или искусного уничтожения следов преступления, а главным образом в результате допущенных следствием ошибок при расследовании, а также в связи с пассивным отношением к информации, полученной по уголовному делу ${ }^{4}$ K сожалению, нередко в ходе расследования упускается из виду пространственно-временной фрактор совершения преступлений, а

с животными и серийными убийствами // Законодательство. 2015. № 2. С. 78-87 ; и др.

${ }^{2}$ См.: Крюкова E. С. Закономерная повторяемость процесса возникновения телесных повреждений (на примере серийных убийств) // Российский следователь. 2020. № 1. С. 9-12.

${ }^{3}$ См.: Крюкова E. C. Криминалистический анализ места совершения преступления - ключ к установлению личности преступника // Судебная реформа в России : прошлое, настоящее, будущее (Кутафинские чтения) : сб. докладов конфр. М., 2015. C. 351-355.

${ }^{4}$ См.: Мазурский В. А. Понятие неочевидных преступлений, их учет, систематизация и совершенствование расследования уголовных дел // Российский следо- 
константная характеристика деятельности преступника в пространстве и времени не входит в доказательственное содержание.

Проведенное исследование показало, что в преступнол поведении серийных убийц возложно выделение вреленных законолерноcmeuั.

Выбор времени совершения преступлений является важным аспектом информации о преступнике. На выбор времени совершения преступления влияет ряд фракторов. Установление времени совершения убийства во всех случаях имеет большое значение. Чем точнее установлено время убийства, тем легче установить личность преступника, проверить причастность к преступлению того или иного лица. Однако большинство имеющихся в литературе рекомендаций по определению времени декларативны, не обосновывают важность установления временного фрактора преступления и не вдаются в подробности тактики определения какого-либо временного интервала или момента времени.

Выбор определенного времени совершения преступления всегда объясним. На совершение преступления, как и на любое другое действие, человек должен иметь время, можно сказать, свободное время. При этом время требуется на каждый этап совершения убийства, включая время на подготовку, поиск потенциальной жертвы, знакомство с ней, нападение, лишение жизни, возможные манипуляции с потерпевшим или трупом, сокрытие следов преступления и пр. Чем сложнее планируемое преступление, тем больше времени оно требует. Совершение серийного убийства не занимает секунды. Дело даже не в сложном комплексе действий, а скорее в эмоциональных переживаниях преступника, которые он получает в ходе деяния.

Некоторые преступники подходят к выбору времени совершения преступления с особой тщательностью, рассчитывая, сколько времени может потребоваться на совершение каждого этапа преступного действия, в том числе чтобы предусмотреть себе алиби на этот промежуток времени. Отмечается, что педофилы нередко проявляют некоторую рациональность в выборе времени совершения преступления и тем, какую стратегию для завоевания доверия детей они используют ${ }^{5}$.

ватель. 2014. № 14. С. 35-40 ; Его же. Организация расследования неочевидных (нераскрытых) преступлений следователями СК РФ // Там же. № 15. С. 3-12.

${ }^{5}$ Cм.: Elliot M., Browne K. \& Kilcoyne J. Child sexual abuse prevention: What offenders tell us // Child Abuse \& Neglect. 1995. № 19. P. 579-594; Young S. The use of normalization as a strategy in the sexual exploitation of children by adult offenders // The Canadian Journal of Human Sexuality. 1997. № 6. P. 285-295 ; Leclerc B., Proulx J. and McKibben A. Modus operandi of sexual offenders working or doing voluntary work with children and adolescents // Journal of Sexual Aggression. 2005. № 2. P. 187-195 ; Leclerc B., Beauregard E., Proulx J. Modus operandi and situational aspects in adolescent sexual offenses against children: a further examination // International Journal of Offender Therapy and Comparative Criminology. 2008. № 52. P. 46-61. 
Время преступления не случайно и во многом предопределено некоторыми субъективными и объективными обстоятельствами. Оно несет информацию о личности убийцы, особенно если выявлены закономерности его выбора при совершении преступлений, т. е. установлены временные сходства эпизодов серии (выходные или праздничные дни, утро или ночь) в сочетании с особенностями убийств. В. А. Образцов пишет: «Закономерность выбора времени совершения преступления определяется по двум направлениям: а) время суток, когда совершаются нападения; б) периодичность совершения нападений (в какие дни, месяцы и т. д.)»6. Следствию необходимо устанавливать год, месяц, число, день недели, время дня, по возможности, до часа и минуты наступления смерти, приходится ли он на рабочий день, день отдыха, государственного или религиозного праздника и пр., проверять и сопоставлять временные фракторы преступления.

Кроме того, следствие должно учитывать продолжительность «серии», временной интервал между преступлениями. Серийное убийство отличает разновременность: наличие двух и более отдельных эпизодов в двух или более отдельных местах с определенной временной паузой (ее часто называют «периодом эмоционального остывания» преступника, «coolingoff period») между убийствами. Интервальность была признана универсальной или общей чертой всех серийных убийств, подтверждается всеми учеными и имеет, по всей видимости, некоторое скрытое значение. Интервалы разнятся, могут увеличиваться или уменьшаться. Отмечаются неодинаковые промежутки времени между отдельными эпизодами, которые со временем учащаются 7 . Единого «периода эмоционального остывания» не существует, у всех серийных убийц он индивидуален. Разные убийцы, так же как и один убийца, имеют разные «периоды остывания». В современной западной литературе выделяются три типа интервалов между серийными убийствами: короткий (менее 14 дней - 14 \%), длительный (более 14 дней - 57 \%) и комбинированный (некоторые эпизоды менее 14 дней, другие - более 14 дней - $29 \%)^{8}$. Однако западные исследователи не приводят конкретных примеров и не дают никаких возможных объяснений данных типов.

Интересна последняя работа израильского ученого А. Эдельштейна, в которой на основе анализа преступной деятельности 53 серийных

${ }^{6}$ Образцов B. А. Серийные убийства как объект психологии и криминалистики : учеб. и практ. пособие. М., 2003. С. 136.

${ }^{7}$ Cм.: Holmes R. M., Holmes S. T. Serial murders. London: Sage, 1998 ; Heuвеmoва Н. В., Усанов И. В. Признаки серийности, особенности их выявления и меры реагирования в ходе расследования преступлений против личности (убийств и изнасилований) : учеб.-метод. пособие. М., 2009. С. 8.

${ }^{8}$ Cм.: Simkin D., Roychowdhury V. P. Statistical study of time intervals between murders for serial killers // Physics and Society, 2018. URL: https://arxiv.org/ abs/1811.00664 


\section{Вестник ВГУ. Серия: Право}

убийц демонстрируются важные временные закономерности убийств ${ }^{9}$. Отмечается, что первые три убийства имеют более длительные «периоды охлаждения», чем последующие (самый длинный интервал между первым и вторым убийством, далее - между вторым и третьим). Периоды между третьим и восьмым убийствами варьировались в среднем от 7,59 до 9,26 месяцев. Период между всеми последующими убийствами в среднем становился короче и составлял от 0,63 до 3,20 месяцев. Около половины (49\%, 26 из 53) изученных серийных убийц совершили 6 убийств; $15 \%$ (8 из 53) совершили 10 убийств; 8 \% (4 из 53) совершили 16 убийств и только один убийца - 17 убийств. Лица, которые совершали более 10 убийств, имели относительно схожие паузы между убийствами, в то время как те, кто совершает менее 10 убийств, имели относительно высокую разнородность между их периодами. Изученные нами дела частично подтверждают выводы А. Эдельштейна. Например, преступная деятельность Чикатило А. Р. развивалась поступательно: до убийств совершал развратнье действия сексуального характера (1973, два эпизода в 1978, 1980), первое убийство совершено в 1978 г., далее в 1981, сель эпизодов в 1982, спустя 6 месяиев преступная деятельность продолжена в июле 1983 и пр. $)^{10}$.

Между первым и вторым преступлением Криштопь В. В. интервал составил 34 днл, между вторылм и третьим - 12 дней ${ }^{11}$. Восемь преступлений Муханкиныл В. А. были совершены в течение фбевраля-лая 1995 г., однако до этого он уже илел две судимости ${ }^{12}$.

Данный аспект темы поднимается нами в отечественной литературе впервые, выявленные корреляции требуют дальнейшего уточнения исходя из российской следственной практики.

В литературе даются различные объяснения временной паузе между убийствами. Психологи отмечают, что она должна быть достаточна для включения различных сложных психологических процессов убийцы во время и после убийства, что особо заметно в рамках диссоциативного расстройства идентичности, когда человек «переключается» от нормальной к агрессивной личности ${ }^{13}$. Подобная идентичность связана с признанием

${ }^{9}$ Cm.: Edelstein A. Cooling-Off Periods among Serial Killers // Journal of Psychology \& Behavior Research. 2020. Vol. 2, № 1. URL: http://www.scholink.org/ojs/index.php/ jpbr/article/view/2524/2611 (дата обращения: 20.05.2020).

10 Чикатило Андрей Романович, уголовное дело № 2-70/1992, Ростовский областной суд.

${ }^{11}$ Криштопа Владимир Васильевич, уголовное дело №2-66/96, Ростовский областной суд.

${ }_{12}$ Муханкин Владимир Анатольевич, уголовное дело № 2-189/96, Ростовский областной суд.

${ }^{13}$ Cм.: Van Der Hart O., Nijenhuis E.R.S., Steele K. Dissociation: An insufficiently recognized major feature of complex PTSD // Journal of Traumatic Stress. 2005. № 18 (5). P. 413-423. URL: https://doi.org/10.1002/jts.20049 (дата обращения: 20.05.2020) ; Edelstein A. Case studies in multiple victims' murder // Juniper Online Journal of Case Studies. 2017. № 2 (4). URL: https://doi.org/10.19080/jojcs.2017.02.555595 (дата обращения: 20.05.2020). 
своей «темной стороны», которую убийца сначала пытается подавлять, а затем все больше размышлять об убийствах ${ }^{14}$. После первых убийств виновный, вероятно, находится в сильном и длительном әмоциональном состоянии, переживаниях, мучениях или, наоборот, удовольствии и какое-то время будет удерживать себя от совершения новых убийств; однако после ряда убийств интервал может становиться короче ${ }^{15}$. В связи с этим следствию важно установить жертв серийных убийств в хронологическом порядке, выявив первое убийство, которое может содержать следы и данные о личности виновного. Чем больше человек совершает антиобщественных действий, тем легче они для него становятся; потеря личного внутреннего конфликта позволяет ему действовать быстрее, чем раньше. Выделяется следующая корреляция возраста и преступной деятельности: чем моложе убийца во время первого убийства, тем больше времени проходит между первым и последующими убийствами ${ }^{16}$. Другие ученые иногда связывают разновременность серийных убийств с поиском жертвы, подготовкой преступления, широкой географией преступной деятельности и пр. ${ }^{17}$ Каких-либо отечественных статистических или научно-практических исследований на эту тему пока нет. Данная гипотеза требует уточнения в российской практике и должна быть рассмотрена в будущих исследованиях.

Вместе с тем важно не только установить временной интервал между эпизодами, но и использовать сведения о нем в расследовании. Зарубежные криминалисты сводят роль «периодов эмоционального остывания» к профилактике и профилированию, но ограничиваться ими не может. Анализ времени совершения преступлений (например, когда началась серия и продолжается ли она до сих пор) может дать информацию о примерном возрасте подозреваемого. Временной перерыв между эпизодами (сериями) может быть результатом изменения обстоятельств в жизни серийного убийцы, в том числе связан с переездами, привлечением к уголовной или административной ответственности, какими-то личными событиями виновного, изменением семейного положения, заболеванием

${ }^{14}$ Cм.: Sykes G., Matza D. Techniques of neutralization: A theory of delinquency // American Journal of Sociology. 1957. № 22. P. 664-670. URL: https://doi. org/10.2307/2089195 ; Бухановский А. О., Бухановская О. А. Психические расстройства у серийных сексуальных преступников : аналитический обзор. Ростов н/Д., 2003.

${ }^{15}$ Cм.: Holmes R. M., DeBurger J. D. Serial murder. London: Sage, 1988 ; Levin J. Serial killers and sadistic murders. New York: Prometheus Books, 2008 ; Edelstein A. Multiple-victims murder. Tel Aviv: eBookPro, 2014.

${ }^{16}$ Cm.: Edelstein A. Cooling-Off Periods among Serial Killers // Journal of Psychology \& Behavior Research. 2020. Vol. 2, № 1. URL: http://www.scholink.org/ojs/index. php/jpbr/article/view/2524/2611 (дата обращения: 20.05.2020).

${ }^{17}$ Cм.: Greswell D. M., Hollin C. R. Multiple murder: A review // The British Journal of Criminology. 1994. № 34(1). P. 1-14. URL: https://oi.org/10.1093/ oxfordjournals.bjc.a048379 (дата обращения: 20.05.2020) ; Osborne J. R., Salfati C. G. Re-conceptualizing "cooling off periods" in serial homicide // Homicide Studies. 2015. № 19 (2). P. 188-205. URL: https://doi.org/10.1177/1088767914526716 


\section{Вестник ВГУ. Серия: Право}

и пр. Серия убийств может быть прервана смертью преступника. Думается, что следствию необходимо устанавливать не только местонахождение подозреваемого, обвиняемого в день совершения преступления, но и сведения о личных, социальных событиях его жизни, психологических состояниях в интервалах между убийствами, соотнося их между собой и, возможно, оценивая как фракторы, значительно повлиявшие на изменение «преступного почерка», времени, места совершения преступлений и пр. Наприлер, в деле Чикатило А. Р. бьли длительные интерваль в 9 мес. в 1981-1982 га., 6 мес. в 1982-1983 г2., которые, к сожалению, на тот молент не были проанализированы ${ }^{18}$. Возможен анализ указанных фрактов на взаимосвязь паузы преступной деятельности и, например, судимости с соответствующим поиском по базам судимых, включая дактилоскопический, геномный учет, учет фрото- и видеоданных и др.

«Временной след» дает информацию о географиии, темпе, последовательности, длительности, моменте времени, когда было совершено единичное преступление, сколько времени было затрачено на организацию преступления, подготовку средств и орудий, сокрытие преступных следов, а также их связи и отношения в рамках эпизода и цепочки преступлений, иногда приводя на первый взгляд разрозненные события в целостную систему. Правоохранительным органам рекомендуется использовать средства визуализации для наглядной хронологии преступной деятельности серийного убийцы. В силу большого количества информации по делу, следствие не всегда имеет возможность быстро увидеть совпадение и взаимосвязь полученных данных. Метод визуализации предназначен для сложных информационных комбинаций и позволяет сосредоточить внимание на существенных моментах, лучше объяснить хронологические связи и последовательное построение информационных потоков (причина - действие - следствие), а также способствует процессу криминалистического мышления. Предлагается беспрецедентная попытка синтезировать криминалистику, хронологию событий, активно используемую в гуманитарных науках, и принципы графической коммуникации. Для объяснения корреляции и взаимосвязи между влияющими значениями могут быть использованы табличные и графические методы представления данных, например схемы, диаграммы, программное обеспечение для создания хронологических срезов, аналитической и графической части следственной работы ${ }^{19}$. Стоит иметь в виду, что визуальное единообразие всегда сигнализирует о неком совпадении признаков, единстве преступной деятельности и может способствовать быстрому и эфффективному расследованию преступлений.

18 Чикатило Андрей Романович, уголовное дело № 2-70/1992, Ростовский областной суд.

${ }^{19}$ Например, приложение для визуализации хронологии Aeon Timeline, дающее наглядную хронологическую шкалу и раскадровку дел, временную шкалу для построения архитектуры дела, связи событий с обнаруженными следами, показаниями свидетелей и другими доказательствами. 


\section{Библиографический список}

Крюкова E. C. Закономерная повторяемость процесса возникновения телесных повреждений (на примере серийных убийств) // Российский следователь. 2020. № 1. С. 9-12.

Крюкова $E$. C. Криминалистический анализ места совершения преступления - ключ к установлению личности преступника // Судебная редрорма в России : прошлое, настоящее, будущее (Кутафинские чтения) : сб. докладов конфр. М. : МГЮА, 2015. С. 351-355.

Нецветова Н. В., Усанов И. В. Признаки серийности, особенности их выявления и меры реагирования в ходе расследования преступлений против личности (убийств и изнасилований) : учеб.-метод. пособие. М. : Юрлитинфором, 2009. $104 \mathrm{c}$.

Образиов B. A. Серийные убийства как объект психологии и криминалистики : учеб. и практ. пособие. М. : Омега-Л, ИМПЭ имени А. С. Грибоедова, 2003. 208 c.

Edelstein A. Cooling-Off Periods among Serial Killers // Journal of Psychology \& Behavior Research. 2020. Vol. 2, № 1 .

Elliot M., Browne K. \& Kilcoyne J. Child sexual abuse prevention: What offenders tell us // Child Abuse \& Neglect. 1995. № 19. P. 579-594.

Greswell D. M., Hollin C. R. Multiple murder: A review // The British Journal of Criminology. 1994. № 34(1). P. 1-14.

Holmes R. M., DeBurger J. D. Serial murder. London: Sage, 1988.

Simkin D., Roychowdhury V. P. Statistical study of time intervals between murders for serial killers // Physics and Society, 2018.

Sykes G., Matza D. Techniques of neutralization: A theory of delinquency // American Journal of Sociology. 1957. № 22. P. 664-670.

Van Der Hart O., Nijenhuis E.R.S., Steele K. Dissociation: An insufficiently recognized major feature of complex PTSD // Journal of Traumatic Stress. 2005. № 18 (5). P. 413-423.

\section{References}

Kryukova E. S. Regular recurrence of the process of occurrence of bodily injury (by the example of serial murders) // Russian Investigator. 2020. № 1. P. 9-12.

Kryukova E. S. Forensic analysis of a crime scene - the key to identifying a criminal // Judicial reform in Russia: past, present, future (Kutafin readings): Sat. report conf. M. : MGYuA, 2015. P. 351-355.

Netsvetova N. V., Usanov I.V. Signs of seriality, peculiarities of their identification and response measures during the investigation of crimes against the person (murders and rapes): a teaching aid. M. : Ed. Jurlitinform. 2009. 104 p.

Obraztsov V. A. Serial murders as an object of psychology and forensic science. Educational and practical guide. M. : Omega-L, IMPE them. A. S. Griboyedov, 2003. 208 p.

Edelstein A. Cooling-Off Periods among Serial Killers // Journal of Psychology \& Behavior Research. 2020. Vol. 2, № 1.

Elliot M., Browne K. \& Kilcoyne J. Child sexual abuse prevention: What offenders tell us // Child Abuse \& Neglect. 1995. № 19. P. 579-594. 
Greswell D. M., Hollin C. R. Multiple murder: A review // The British Journal of Criminology. 1994. № 34(1). P. 1-14.

Holmes R. M., DeBurger J. D. Serial murder. London : Sage, 1988.

Simkin D., Roychowdhury V. P. Statistical study of time intervals between murders for serial killers // Physics and Society, 2018.

Sykes G., Matza D. Techniques of neutralization: A theory of delinquency // American Journal of Sociology. 1957. № 22. P. 664-670.

Van Der Hart O., Nijenhuis E.R.S., Steele K. Dissociation: An insufficiently recognized major feature of complex PTSD // Journal of Traumatic Stress. 2005. № 18 (5). P. 413-423.

\section{Для цитирования:}

Крюкова E. C. Устойчивость и повторяемость преступной деятельности в пространстве и времени как закономерность серийных убийств // Вестник Воронежского государственного университета. Серия: Право. 2021. № 3 (46). С. 264-272. DOI:https:// doi.org/10.17308/vsu.proc.law.2021.3/3556

\section{Recommended citation:}

Kryukova E. S. Sustainability and repeatability of criminal activities in area and time as a feature of serial killing // Proceedings of Voronezh State University. Series: Law. 2021. № 3 (46). P. 264-272. DOI: https://doi.org/10.17308/vsu.proc.law.2021.3/3556

Московский государственный университет илени М. В. Лолоносова

Крюкова Е. С., ассистент кафбедры криминалистики юридического фбакульmema

E-mail: zkrukova@mail.ru
Lomonosov Moscow State University $(M S U)$

Kryukova E. S., Assistant of the Criminalistics of the Law Faculty Department E-mail:zkrukova@mail.ru 